\title{
Numerical Analysis of Earthquake Load Mitigation on Rigid Retaining Walls Using EPS Geofoam
}

\author{
Deling Wang ${ }^{1, *}$ and Richard J. Bathurst ${ }^{2}$ \\ ${ }^{I}$ School of Urban Construction, Yangtze University, Jingzhou 434023, Hubei, China \\ ${ }^{2}$ Civil Engineering Department, Royal Military College of Canada, Kingston K7K 7B4, Canada
}

\begin{abstract}
The mitigation of seismic-induced dynamic earth forces by placing a vertical layer of expanded polystyrene (EPS) geofoam buffer between a rigid retaining wall and the backfill soil is a recent geotechnical innovation. In this paper, the influence of an EPS geofoam buffer on the reduction of dynamic wall forces is numerically studied by simulating the results of three reduced-scale models of rigid walls mounted on a large shaking table. Numerical simulations were carried out using the finite element program ABAQUS. The paper shows that the numerical results capture the trend in earth forces with increasing base acceleration for all three models. The quantitative dynamic load-time response from the numerical simulations was also judged to be in good agreement with measured physical test values. The numerical trend of EPS geofoam also is the same as that of measured test data. With the increasing time, the compression of EPS geofoam increases. And softer EPS geofoam produces more compression which takes more vibration energy by its deformation. The numerical results confirm the results of physical tests that demonstrate that EPS geofoam seismic buffers hold great promise to reduce earthquake-induced dynamic loads against rigid retaining wall structures.
\end{abstract}

Keywords: Expanded Polystyrene (EPS) geofoam, Retaining wall, Wall force, Shaking table test.

\section{INTRODUCTION}

Expanded polystyrene (EPS) geofoam is a lightweight polymeric material which is made by expansion of raw plastic beads. When expanded, the EPS beads become spherical-shaped particles containing closed hollow cells. The role of EPS as an innovative lightweight building material is now well recognized due to its low density, but high compressive and rupture strength.

Rigid earth retaining wall structures are common civil engineering infrastructure but may be vulnerable to catastrophic failure during earthquakes. Post-earthquake surveys have revealed that many retaining walls suffered damage due to large displacements. However, the increased thrust from the backfill can be mitigated by using a suitably selected lightweight construction material. Inglis [1] reported the first use of EPS geofoam as a seismic buffer to reduce potential seismic earth loads against a non-yielding basement wall. Gaskin [2] and Bathurst et al., [3] carried out reducedscale shaking table tests on a rigid retaining wall protected by EPS geofoam. The test data showed that the peak lateral loads acting on the compressible model walls were reduced below values measured for the nominally identical structure but with no compressible inclusion.

Researchers have used different numerical approaches to investigate the use of seismic buffers to protect retaining walls: a simple displacement-type block model [4], a

\footnotetext{
*Address correspondence to this author at the School of Urban Construction, Yangtze University, Jingzhou 434023, Hubei, China; Tel: +86-716-8060151; Fax: +86-716-8060710;

E-mails: delingw@gmail.com, sjhwdl@163.com
}

multiple horizontal layer model [5], and the finite difference program FLAC [6]. In this paper, numerical simulations were carried out using the finite element program ABAQUS. Results are compared to measurements from reduced-scale physical models of rigid walls with and without a geofoam seismic buffer.

\section{SHAKING TABLE TESTS AT RMC}

The physical tests described in this paper were carried out on a $2.7 \mathrm{~m} \times 2.7 \mathrm{~m}$ shaking table located at the Royal Military College of Canada (RMC). The physical models were 1-m-high by $1.4-\mathrm{m}$-wide. A rigid wall constructed from a stiffened aluminum bulkhead was attached to the shaking table platform and used to retain a synthetic granular soil. Dry synthetic olivine sand was used as the backfill and was vibro-compacted in $200 \mathrm{~mm}$ lifts. The backfill extended $2 \mathrm{~m}$ beyond the model wall at the front of the strong box. The inside surfaces of the sidewalls of the strong box were covered by a friction-reducing membrane which when combined with rigid lateral bracing ensured that the test models were subjected to plane strain boundary conditions. A geofoam block $150 \mathrm{~mm}$ thick was placed as a buffer between the rigid wall and the backfill. One control test without the geofoam seismic buffer was also carried out to quantify the performance due to the presence of the geofoam buffer to reduce dynamic loads on the rigid wall. The shaking table was driven in the horizontal direction only. A stepped-amplitude sinusoidal acceleration record with a frequency of $5 \mathrm{~Hz}$ was applied to the base of the models in all tests. The acceleration amplitude was increased at 5second intervals $(0.05 \mathrm{~g}$ increments $)$ up to peak base 
acceleration amplitude in excess of $0.8 \mathrm{~g}$ and the test terminated.

\section{NUMERICAL MODELS}

The numerical simulations were carried out using the finite element program ABAQUS. Three numerical models were set up for three wall tests, wall 1 without EPS geofoam buffer while wall 2 with EPS density $16 \mathrm{~kg} / \mathrm{m}^{3}$ and wall 3 with EPS density $12 \mathrm{~kg} / \mathrm{m}^{3}$. The thickness of the geofoam was taken as $150 \mathrm{~mm}$ to match the physical tests. The finite element model for the simulation of the shaking table tests is shown in Fig. (1).

ABAQUS mainly consists of two analysis modules: one is ABAQUS/Standard, another is ABAQUS/Explicit. ABAQUS/Standard is a general-purpose finite element program while ABAQUS/Explicit is an explicit dynamics program which provides nonlinear, transient, dynamic analysis of solids and structures using explicit time integration. For the numerical simulation in this paper, since the dynamic loads (acceleration excitation) last about 100 seconds and the ABAQUS model with 945 nodes and 860 elements (as in Fig. 1) is not complicated, so ABAQUS/ Standard is selected to run the analysis.

Soil Properties. The backfill soil was modeled as a MohrCoulomb plasticity material. This model allows elastic behavior up to yield (Mohr - Coulomb yield point defined by the friction angle), and plastic flow at post-yield under constant stress. Based on the results of direct shear box tests on specimens of the same sand material and data adopted by Bathurst et al., [4] and Saman et al. [6], the soil properties are summarized in Table $\mathbf{1}$.

EPS Geofoam Properties. Many researchers have studied the properties of EPS geofoam. Horvath [7] divided a typical
Table 1. Soil Properties

\begin{tabular}{|l|l|}
\hline Parameter & Value \\
\hline \hline Soil density $[\mathrm{kg} / \mathrm{m} 3]$ & 1550 \\
\hline Friction angle & $51^{\circ}$ \\
\hline Dilation angle & $15^{\circ}$ \\
\hline Elastic modulus $[\mathrm{MPa}]$ & 15.2 \\
\hline Poisson's ratio & 0.086 \\
\hline
\end{tabular}

stress-strain curve from a short-term test of EPS into three key stages: the first stage exhibits linear-elastic behavior up to between 1 and 2\% strain; the second stage includes yield which occurs at greater strain; the third stage features postyield work-hardening behavior. Manufacturers have also reported an elastic strain limit of $1 \%$ based on rapid uniaxial compression tests. In the two physical tests with EPS geofoam, the measured compressive strains in the geofoam buffer were less than $1 \%$. Hence, the geofoam buffer material was modeled as a linear elastic-plastic material although there are more advanced models in the ABAQUS program, e.g. hyper foam and crushable foam for foam materials. EPS density can be a useful index property because the relevant mechanical engineering properties of EPS correlate well with density. Properties of geofoam buffer with the two densities used in this investigation are summarized in Table 2.

Contact Interaction and Boundary Conditions. Contact interactions were defined between the geofoam and sand interface. This interface allowed the soil and buffer to separate with no tensile stress although this separation was

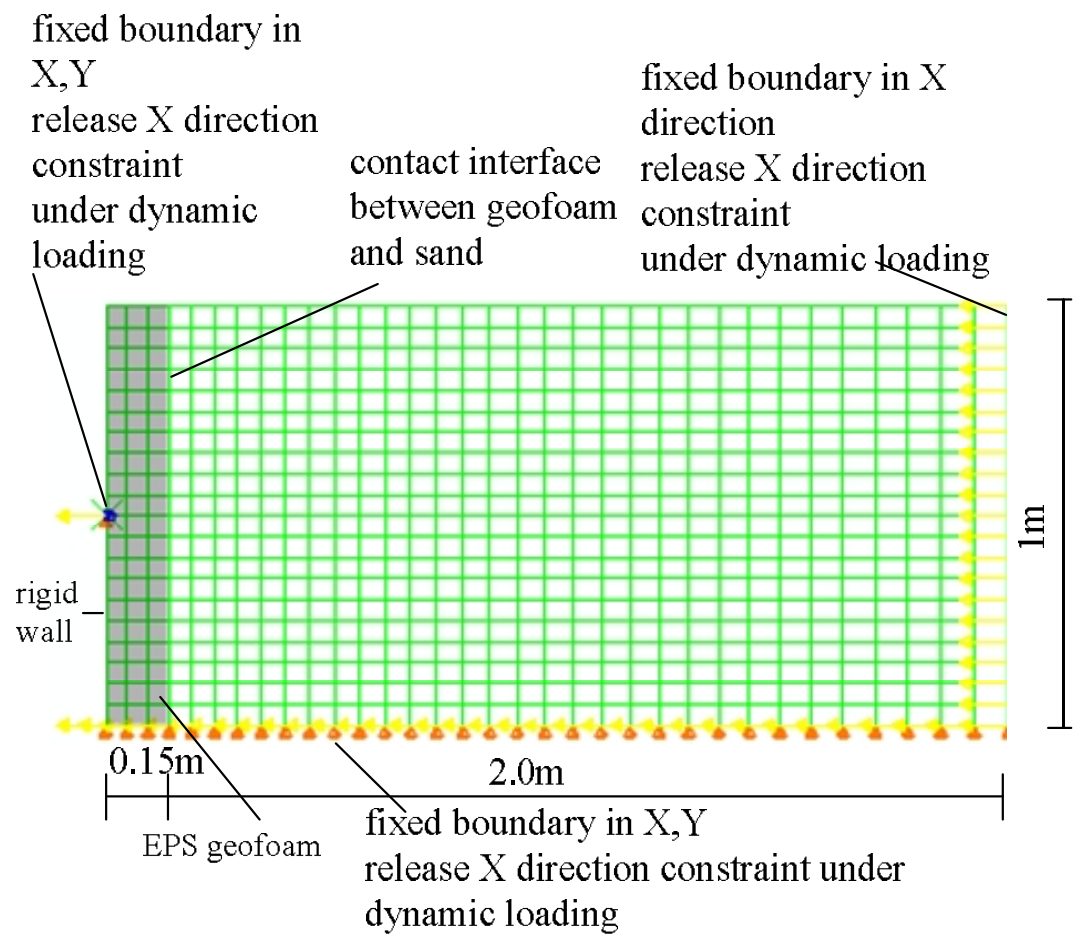

Fig. (1). Numerical model for shaking table tests. 
not observed in the physical models. An interface friction angle of $15^{\circ}$ was assumed based on recommendations by [8]. For the control case, an interface shear friction angle of $17^{\circ}$ was assumed for the aluminum-sand interface based on published metal-sand friction angles [9]. For contact pairs, a hard contact was used in the normal direction. Since the EPS foam was firmly held against the aluminum plate (wall) by the lateral pressure from the soil, the geofoam was assumed to be bonded to the rigid wall. The boundary displacements were fixed in the $\mathrm{X}$ and $\mathrm{Y}$ direction during construction but excited only in the $\mathrm{X}$ direction during simulated shaking (Fig. 1).

Dynamic Loading. In all physical models, the same target stepped-amplitude sinusoidal record with a frequency of $5 \mathrm{~Hz}$ was used as the horizontal base excitation history. A $5 \mathrm{~Hz}$ frequency at $1 / 6$ model scale corresponds to $2 \mathrm{~Hz}$ at prototype scale according to the scaling laws proposed by Iai [10]. Frequencies of $2-3 \mathrm{~Hz}$ are representative of typical predominant frequencies of medium to high frequency earthquakes [11]. Nevertheless, this simple base excitation record is more aggressive than an equivalent true earthquake record with the same predominant frequency and amplitude.

Natural Frequency of the Numerical Models. The fundamental frequency of the numerical model walls was evaluated to ensure that the predominant frequency of the input motion would not generate a resonance condition which could in turn control system response and lead to premature failure.

This analysis was carried out by the frequency extraction procedure. The frequency extraction procedure is a linear perturbation procedure, and can perform eigenvalue extraction to calculate the natural frequencies and the corresponding mode shapes of a system. Linear perturbation analysis steps are available only in ABAQUS/Standard.

ABAQUS/Standard provides three eigenvalue extraction methods. Between them, the Lanczos method is the default eigenvalue extraction method because it has the most general capabilities. Table $\mathbf{3}$ presents the numerical fundamental frequency of walls calculated by the Lanczos method.

Based on one- and two-dimensional elastic theory of vibration, the fundamental frequency of a linear elastic media can be expressed as:

$$
f_{1}=G F \times \frac{1}{4 H} \sqrt{\frac{E}{2(1+\mu) \rho}}
$$

where, $G F$ is a geometrical factor used to modify the one dimensional elastic theory expression to account for 2-D

Table 2. EPS Geofoam Properties

\begin{tabular}{|l|l|l|}
\hline \multirow{2}{*}{ Property } & \multicolumn{2}{|c|}{ EPS Density } \\
\cline { 2 - 3 } & $\mathbf{1 6} \mathbf{~ k g} / \mathbf{m}^{\mathbf{3}}$ & $\mathbf{1 2} \mathbf{~ k g} / \mathbf{m}^{\mathbf{3}}$ \\
\hline \hline Elastic modulus [MPa] & 4.5 & 3.3 \\
\hline Poisson's ratio & 0.09 & 0.07 \\
\hline Yield strength $[\mathrm{KPa}]$ & 30.4 & 16.8 \\
\hline
\end{tabular}

Table 3. Numerical Fundamental Frequency of Walls

\begin{tabular}{|l|l|}
\hline Wall Type & Frequency \\
\hline \hline Wall 1 & 21.918 \\
\hline Wall 2 & 21.753 \\
\hline Wall 3 & 21.702 \\
\hline
\end{tabular}

boundary effects, $H$ is wall height, $E$ is elastic modulus, $\mu$ is Poission's ratio, $\rho$ is density. Values for $G F$ under discussion are in the range of 1.24-1.8 adopted by Saman et al. [6]. These solutions with GF computed for the rigid wall case give $f_{1}=20.7-30.2 \mathrm{~Hz}$, which includes the numerical values for the rigid walls reported in Table 3. The free vibration results show that the numerical models used in this investigation were excited at $5 \mathrm{~Hz}$ frequency well below the fundamental frequency of these walls. Hence, numerical and physical test results were not complicated by model resonance.

Construction of the Numerical Models. The plane strain numerical models were constructed in one initial step. The contacts between geofoam buffer and soil were created first. Next, gravity was applied on the models and the models come to achieve equilibrium. Next, a constant amplitude sinusoidal base excitation record of $0.1 \mathrm{~g}$ with a frequency of $9 \mathrm{~Hz}$ was applied for $5 \mathrm{~s}$ to simulate the vibro-compaction that was used in the physical tests to compact the sand backfill in 200-mm-thick lifts. Following compaction, the system was brought to equilibrium once again. In the last step, the base, rigid wall and the right-end vertical boundary of the models were excited using the same base input acceleration record used in the physical tests.

\section{NUMERICAL RESULTS}

Results of Wall Force. Wall force measurements are the most important parameter to quantify seismic wall performance with and without a geofoam buffer inclusion under simulated dynamic earth loading.

Fig. (2a-c) provide a summary of wall force versus time for both physical and numerical experiments. The vertical axis is the horizontal earth force on a per-meter running length of wall basis. For clarity in the figures, only maximum (peak) horizontal forces acting against the rigid wall structure are presented.

A dimensionless variable, 'isolation efficiency' or $I_{\mathrm{E}}$, is defined as follows to measure the attenuation of maximum wall force:

$$
I_{E}=\frac{F_{0}-F}{F_{0}}
$$

where, $F_{0}$ denotes the peak value of wall force when no inclusion is present, $F$ denotes the peak value of wall force with an EPS geofoam inclusion. Variable $I_{\mathrm{E}}$ quantifies the relative isolation effect of EPS geofoam on wall force. Table 4 presents some physical and numerical results for Walls 1,2 , and 3 . 

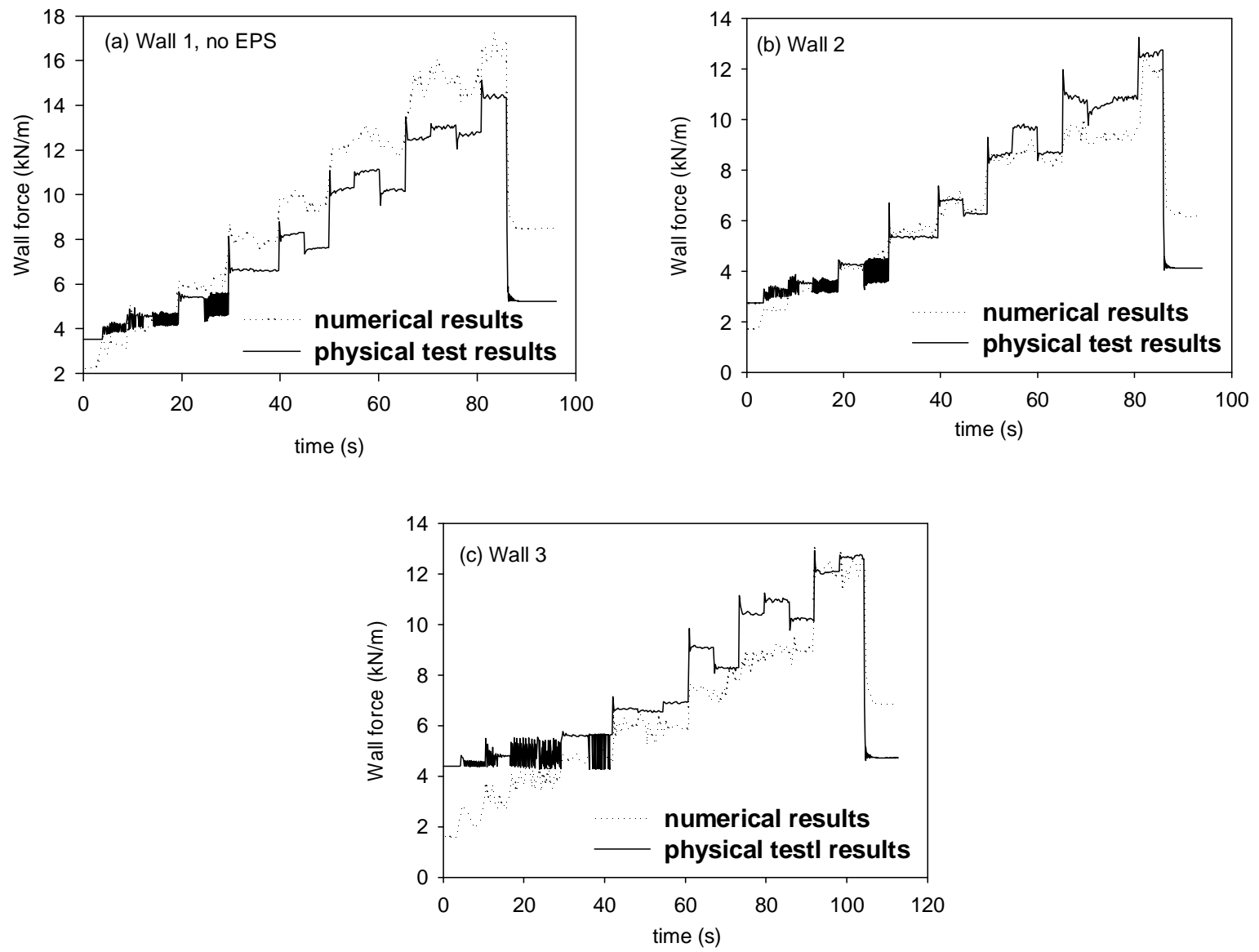

Fig. (2). Maximum wall force-time response for: (a) Wall 1; (b) Wall 2; and (c) Wall 3.

Table 4. Maximum Wall Force and Isolation Efficiency Factor IE

\begin{tabular}{|l|c|c|c|c|}
\hline Wall \# & $\begin{array}{l}\text { Maximum Wall Force } \\
\text { in Physical Test (1) }\end{array}$ & $\begin{array}{l}\text { Maximum Wall Force in } \\
\text { Numerical Simulation (2) }\end{array}$ & IE (\%) in Physical Tests & $\begin{array}{l}\text { Difference between (1) } \\
\text { and (2) (\%) }\end{array}$ \\
\hline \hline Wall 1 & 15117 & 17009 & - & 12.5 \\
\hline Wall 2 & 13263 & 12601 & 12.3 & 5.0 \\
\hline Wall 3 & 12917 & 12846 & 14.6 & 0.6 \\
\hline
\end{tabular}

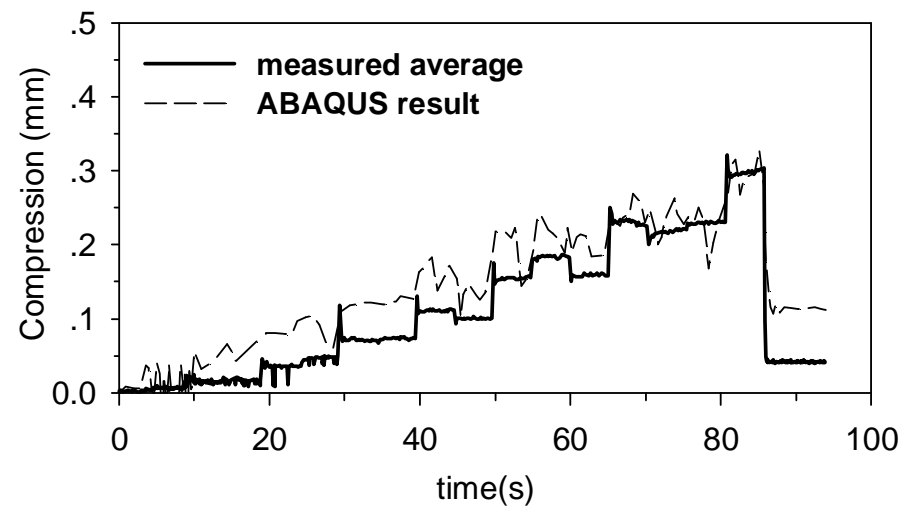

(a) EPS $\rho=16 \mathrm{~kg} / \mathrm{m}^{3}$ 


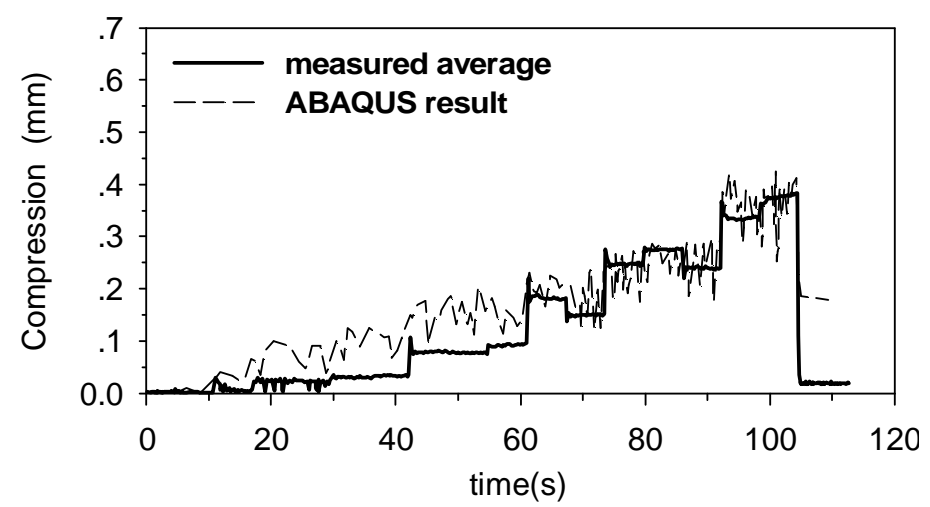

(b) EPS $\rho=12 \mathrm{~kg} / \mathrm{m}^{3}$

Fig. (3). The curves of EPS geofoam compression with time for different EPS type

EPS Compression. Fig. (3) shows the Compression curve of EPS geofoam buffer computed by ABAQUS and recoreded by test instruments. Bolt lines represent the average value of max compression of EPS geofoam buffer recorded by 4 potentiometers. The dotted curves computed by ABAQUS represent the average max compression of EPS geofoam along the height. Fig. (3) shows that with the increasing time, the compression of EPS increases. The trend is the same as that of physical test data. When the density of EPS geofoam decreases from $16 \mathrm{~kg} / \mathrm{m}^{3}$ to $12 \mathrm{~kg} / \mathrm{m}^{3}$, its elastic modulus also decreases, while its compression increases, which means that softer EPS geofoam can take more vibration energy by its deformation.

\section{CONCLUSIONS}

Dynamic force mitigation against a rigid wall due to placement of a geofoam seismic buffer was investigated numerically using a series of finite element models. The compressible EPS geofoam is able to mitigate dynamic load greatly compared to the untreated wall case.

In Table 3, the difference between physical and numerical results for Wall 1 is greater than for Wall 2 and 3. However, based on the complexity of the physical models, the numerical results are judged to be satisfactory. The difference in measured and predicted loads using the two EPS geofoam cases (Wall 2 and 3) is very small. Hence, numerical modeling of geofoam seismic buffers using the finite element program ABAQUS is a promising research tool.

\section{CONFLICT OF INTEREST}

Declared none.

\section{ACKNOWLEDGMENTS}

The Natural Science Project 2010CDA025 of Hubei Province acknowledges the support.

\section{REFERENCES}

[1] D. Inglis, G. Macleod, E. Naesgaard, and M. Zergoun, "Basement wall with seismic earth pressures and novel expanded polystyrene foam buffer layer," In: Proceedings of the Tenth Annual Symposium of the Vancouver Geotechnical Society, Vancouver: Canada, 1996.

[2] A.P. Gaskin, "An Investigation into the use of Expanded Polystyrene for Seismic Buffers”, MSc thesis, Queen's University, Kingston, Canada, 2000.

[3] R.J. Bathurst, S. Zarnani and A. Gaskin, "Shaking table testing of geofoam seismic buffers," Soil Dyn. Earthquake Eng., vol. 4, pp. 324-332, 2007.

[4] R.J. Bathurst, A. Keshavarz, and S. Zarnani, "A simple displacement model for response analysis of EPS geofoam seismic buffers," Soil Dyn. Earthquake Eng., vol. 4, pp. 344-353, 2007.

[5] Y. Wang, and R.J. Bathurst, "Horizontal slice method for force and displacement analysis of eps geofoam seismic buffers for rigid retaining walls", Chinese J. Civil Eng., 10, 73-80, 2008.

[6] S. Zarnani, and R.J. Bathurst, "Numerical modeling of EPS seismic buffer shaking table tests", Geotext. Geomembr., vol. 26, pp. 371383, 2008.

[7] J. S. Horvath, "Expanded polystyrene (eps) geofoam: An introduction to material behavior", Geotext. Geomembr., vol. 13 pp. 263-280, 1994.

[8] V.C. Xenaki, and G.A. Athanasopoulos, "Experimental investigation of the interaction mechanism at the eps geofoam-sand interface by direct shear testing", Geosynth.. Int., vol. 6, pp. 471-499, 2001.

[9] S.L. Kramer, Geotechnical Earthquake Engineering, Prentice-Hall press, USA, 1996.

[10] S. Iai, "Similitude for shaking table tests on soil-structure-fluid model in 1g gravitational field", Soils Found., vol. 1, pp. 105-118, 1989.

[11] R.J. Bathurst, and K. Hatami, "Seismic response analysis of a geosynthetic reinforced soil retaining wall", Geosynth. Int., vol. 5, pp. 127-166, 1998. 